\begin{tabular}{|c|c|c|c|c|c|c|}
\hline \multirow{4}{*}{ Impact Factor: } & ISRA (India) & $=3.117$ & SIS (USA) & $=0.912$ & ICV (Poland) & $=6.630$ \\
\hline & ISI (Dubai, UAE & $=0.829$ & РИНЦ (Russia) & $=0.156$ & PIF (India) & $=1.940$ \\
\hline & GIF (Australia) & $=0.564$ & ESJI (KZ) & $=\mathbf{5 . 0 1 5}$ & IBI (India) & $=4.260$ \\
\hline & JIF & $=1.500$ & SJIF (Morocco & $=5.667$ & & \\
\hline
\end{tabular}

\begin{tabular}{|c|c|}
\hline $\begin{array}{l}\text { SOI: } \underline{1.1 / 7} \\
\text { International S} \\
\text { Theoretical } \mathbf{\&}\end{array}$ & 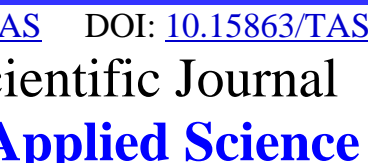 \\
\hline p-ISSN: 2308-4944 (print) & e-ISSN: 2409-0085 (online) \\
\hline Year: 2018 & Volume: 68 \\
\hline Published: 30.12 .2018 & tttp://T-Science.org \\
\hline
\end{tabular}

SECTION 1. Theoretical research in mathematics
QR - Issue
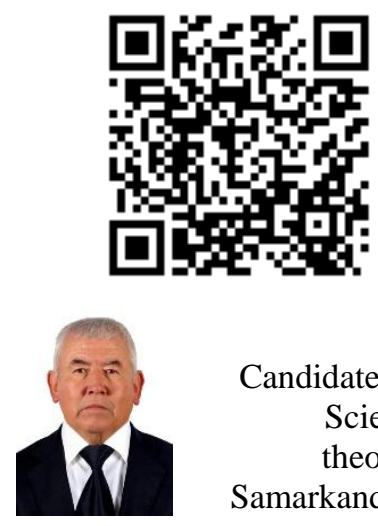

Ablakul Abdirashidov

Candidate of Physical and Mathematical Sciences, Docent to department of theoretical and applied mechanics, Samarkand State University, Uzbekistan, abdira@mail.ru

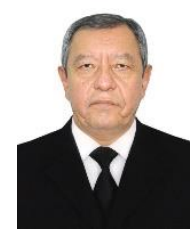

Abduvali Karshiyev Candidate of Physical and Mathematical Sciences, Head of department of Computer engineering, Tashkent university information technology Samarkand State University, Uzbekistan

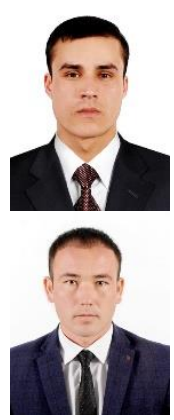

Bekzod Ortikov

Student of Mechanical and Mathematical Faculty, Samarkand State University, Uzbekistan

Nurshod Kadirov Student of Mechanical and Mathematical Faculty, Samarkand State University, Uzbekistan

\title{
APPLICATION OF APPROXIMATE ADOMIAN DECOMPOSITION METHOD AND A VARIATIONAL ITERATIONS METHOD TO SOLVING A CAUCHY PROBLEM WITH THE HEAT DISSIPATION AND LAPLACE EQUATIONS
}

Abstract: In this paper, the Cauchy problem with the heat dissipation and Laplace equations is solved analytically using the Adomian decomposition method and the variational iteration method. It is shown that these methods are the most effective and convenient for solving some evolution equations. The obtained approximate solutions were compared, the results of these methods are the same; while the method of decomposition of Adomian can be much simpler, more convenient and more efficient to approach such problems as compared to the method of variational iteration and other traditional methods.

Key words: equations of heat dissipation and Laplace, Cauchy problem, variational iteration method, Adomian decomposition method, exact solutions.

Language: English

Citation: Abdirashidov, A., Karshiyev, A., Ortikov, B., \& Kadirov, N. (2018). Application of approximate adomian decomposition method and a variational iterations method to solving a Cauchy problem with the heat dissipation and Laplace equations. ISJ Theoretical \& Applied Science, 12 (68), 323-329.

Soi: http://s-o-i.org/1.1/TAS-12-68-48 Doi: crossef https://dx.doi.org/10.15863/TAS.2018.12.68.48

\section{Introduction.}

Nonlinear phenomena are of fundamental importance in various fields of science and technology. Nonlinear models of real-world problems are still difficult to solve either numerically or theoretically. Recently, much attention has been paid to the search for better and more efficient approximate or exact, analytical or numerical methods for solving for nonlinear models [10,11]. There are many standart semi-analytical methods for 


\begin{tabular}{|c|c|c|c|c|c|c|}
\hline \multirow{4}{*}{ Impact Factor: } & ISRA (India) & $=3.117$ & SIS (USA) & $=0.912$ & ICV (Poland) & $=6.630$ \\
\hline & ISI (Dubai, UAE & $=0.829$ & РИНЦ (Russia & $=0.156$ & PIF (India) & $=1.940$ \\
\hline & GIF (Australia) & $=0.564$ & ESJI (KZ) & $=5.015$ & IBI (India) & $=4.260$ \\
\hline & JIF & $=1.500$ & SJIF (Morocco & $=5.667$ & & \\
\hline
\end{tabular}

solving linear and nonlinear partial differential equations, for example, the Adomian decomposition method $[2,11]$ and the variational iterations method [7-10]. The Adomian decomposition method and the variational iterations method is one of the wellknown methods for solving various linear and nonlinear evolution equations. Many studies have proven that these methods are reliable and effective for a wide range of scientific applications, linear and nonlinear equations with bounded and unbounded domains $[2-7,10,11]$. These methods have no special requirements, such as linearization, small parameters, and so on for nonlinear operators. Below, the Cauchy problem with heat dissipation and Laplace equations are solved analytically using the Adomian decomposition method and variational iterations method.

$\mathbf{1}^{\mathbf{0}}$. Setting the first problem. It is required to solve approximately the following Cauchy problem with the heat equation in $n$ dimensional space using the Adomian decomposition method and variational iterations method:

$$
\begin{gathered}
u_{t}(x, t)=a^{2} \Delta u(x, t), \quad x \in R^{n}, t>t_{0}, \\
\left.u(x, t)\right|_{t=t_{0}}=f(x)
\end{gathered}
$$

where $x=\left(x_{1}, x_{2}, \ldots, x_{n}\right)$ - is a point in $R^{n}$ space, $\Delta=\frac{\partial^{2}}{\partial x_{1}^{2}}+\frac{\partial^{2}}{\partial x_{2}^{2}}+\ldots+\frac{\partial^{2}}{\partial x_{n}^{2}}-$ Laplace operator, $u(x, t)$ - unknown function (temperature function), $f(x)$ - given function (temperature at $t=t_{0}$ time).

Algorithm for solving the first problem. To solve this problem, we will use the Adomian decomposition method and variational iterations method.

1.1. Adomian decomposition method (ADM). By the idea of an ADM, we have:

$$
\begin{aligned}
& \int_{t_{0}}^{t} u_{\xi}(x, \xi) d \xi=\int_{t_{0}}^{t} a^{2} \Delta u(x, \xi) d \xi \Rightarrow \\
& u(x, t)=f(x)+\int_{t_{0}}^{t} a^{2} \Delta u(x, \xi) d \xi \\
& u(x, t)=\sum_{n=0}^{\infty} u_{n}(x, t) \Longrightarrow \\
& u_{0}(x, t)+u_{1}(x, t)+u_{2}(x, t)+\ldots=f(x)+ \\
& +\int_{t_{0}}^{t} a^{2} \Delta\left[u_{0}(x, \xi)+u_{1}(x, \xi)+u_{2}(x, \xi)+\ldots\right] d \xi
\end{aligned}
$$

Then we have

$$
\begin{aligned}
& u_{0}(x, t)=f(x) \\
& u_{1}(x, t)=\int_{t_{0}}^{t} a^{2} \Delta u_{0}(x, \xi) d \xi=\left(t-t_{0}\right) \cdot a^{2} \Delta f(x) \\
& u_{2}(x, t)=\int_{t_{0}}^{t} a^{2} \Delta u_{1}(x, \xi) d \xi=\frac{\left(t-t_{0}\right)^{2}}{2 !} \cdot a^{4} \Delta^{2} f(x) \\
& \ldots ; u_{n}(x, t)= \\
& =\int_{t_{0}}^{t} a^{2} \Delta u_{n-1}(x, \xi) d \xi=\frac{\left(t-t_{0}\right)^{n}}{n !} \cdot a^{2 n} \Delta^{n} f(x)
\end{aligned}
$$

and so on.

Finally we find the solution to the problem:

$$
\begin{aligned}
& u(x, t)=u_{0}(x, t)+u_{1}(x, t)+u_{2}(x, t)+ \\
& +\ldots=\sum_{n=0}^{\infty} \frac{\left(t-t_{0}\right)^{n}}{n !} \cdot a^{2 n} \Delta^{n} f(x)
\end{aligned}
$$

1.2. Variational iterations method (VIM). According to the idea of VIM we have:

$$
\begin{aligned}
& u_{n+1}(x, t)=u_{n}(x, t)+ \\
& +\int_{t_{0}}^{t} \lambda(\xi)\left[\frac{\partial v_{n}(x, \xi)}{\partial \xi}-a^{2} \Delta \tilde{v}_{n}(x, \xi)\right] d \xi .
\end{aligned}
$$

Where $\lambda(\xi)$ - Lagrange multiplier, and for the stationary case $\left.\lambda^{\prime}(\xi)\right|_{\xi=t}=0,1+\left.\lambda(\xi)\right|_{\xi=t}=0$ and then we have $\lambda(\xi)=-1$.

$$
\begin{aligned}
& u_{n+1}(x, t)=u_{n}(x, t)- \\
& -\int_{t_{0}}^{t}\left[\frac{\partial v_{n}(x, \xi)}{\partial \xi}-a^{2} \Delta \tilde{v}_{n}(x, \xi)\right] d \xi .
\end{aligned}
$$

Applying VIM, we get the following results:

$$
\begin{gathered}
u_{0}(x, t)=u\left(x, t_{0}\right)=f(x) \\
u_{1}(x, t)=f(x)+\left(t-t_{0}\right) \cdot a^{2} \Delta f(x) \\
u_{2}(x, t)=f(x)+\left(t-t_{0}\right) \cdot a^{2} \Delta f(x)+ \\
+\frac{\left(t-t_{0}\right)^{2}}{2 !} \cdot a^{4} \Delta^{2} f(x) \text { and so on. }
\end{gathered}
$$

Finally we find the solution to the problem: $u(x, t)=\lim _{n \rightarrow \infty} u_{n}(x, t)=\lim _{n \rightarrow \infty}\left[f(x)+\left(t-t_{0}\right)\right.$.

$a^{2} \Delta f(x)+\frac{\left(t-t_{0}\right)^{2}}{2 !} \cdot a^{4} \Delta^{2} f(x)+\ldots+$

$\left.+\frac{\left(t-t_{0}\right)^{n}}{n !} \cdot a^{2 n} \Delta^{n} f(x)\right]=$

$=\sum_{n=0}^{\infty} \frac{\left(t-t_{0}\right)^{n}}{n !} \cdot a^{2 n} \Delta^{n} f(x)$ 


\begin{tabular}{|c|c|c|c|c|c|c|}
\hline \multirow{4}{*}{ Impact Factor: } & ISRA (India) & $=3.117$ & SIS (USA) & $=0.912$ & ICV (Poland) & $=6.630$ \\
\hline & ISI (Dubai, UAE & $=0.829$ & РИНЦ (Russia & $=0.156$ & PIF (India) & $=1.940$ \\
\hline & GIF (Australia) & $=0.564$ & ESJI (KZ) & $=5.015$ & IBI (India) & $=4.260$ \\
\hline & JIF & $=1.500$ & SJIF (Morocco & $=5.667$ & & \\
\hline
\end{tabular}

We will check for uniform convergence of a given series with the help of the Weierstrass theorem [4].

Theorem (Weierstrassian alert). If each term of the functional series

$$
\begin{aligned}
& \sum_{n=1}^{\infty} u_{n}(x)=u_{1}(x)+u_{2}(x)+ \\
& +u_{3}(x)+\ldots+u_{m}(x)+\ldots
\end{aligned}
$$

in the set $M(M \subset R)$ to satisfy the inequality

$$
\left|u_{n}(x)\right| \leq c_{n} \quad(n=1,2, \ldots)
$$

and is convergent number series

$$
\sum_{n=1}^{\infty} c_{n}=c_{1}+c_{2}+c_{3}+\ldots+c_{m}+\ldots,
$$

then the functional series (4) converges uniformly in the set $M$.

If the function $f(x)$ is continuous in $x \in R^{n}$ and has continuous derivatives in it, then at the $t_{0}<t<T$ time moment for the series (3) the following estimate holds

$$
\begin{aligned}
& |u(x, t)|=\left|\sum_{n=0}^{\infty} \frac{\left(t-t_{0}\right)^{n}}{n !} \cdot a^{2 n} \Delta^{n} f(x)\right| \leq \\
& \leq \sum_{n=0}^{\infty} \frac{p^{n}}{n !}
\end{aligned}
$$

where $p=$ const.

Now we will check for convergence of the $\sum_{n=0}^{\infty} \frac{p^{n}}{n !}$ number series. On the basis of $\mathrm{D}$ 'alembert [4] on the convergence of a numerical series with positive coefficients, we have

$$
\lim _{n \rightarrow \infty} \frac{a_{n+1}}{a_{n}}=\lim _{n \rightarrow \infty} \frac{p^{n+1}}{(n+1) !} \cdot \frac{n !}{p^{n}}=\lim _{n \rightarrow \infty} \frac{p}{n+1}=0<1 .
$$

Then the $\sum_{n=0}^{\infty} \frac{p^{n}}{n !}$ number series converges. From the validity of the estimate (5) and on the basis of the Weierstrass theorem, series (3) uniformly converges. Then, the function $u(x, t)$ is a solution to problem (1)-(2).

Note: If one $\psi(x, t)$ particular solution of the inhomogeneous heat equation is known

$$
u_{t}(x, t)=a^{2} \Delta u(x, t)+\varphi(x, t),
$$

where $\varphi(x, t)$ - known function, then replacing

$$
v(x, t)=u(x, t)+\psi(x, t)
$$

equation (6) can be brought to mind

$$
v_{t}(x, t)=a^{2} \Delta v(x, t),
$$

and solution (8) can be found using (3) or $\left(3^{*}\right)$.
Below are the possibilities of applying formulas (3) or $\left(3^{*}\right)$ in some examples.

Example 1.1. Find an solution of the Cauchy problem with the heat equation:

$$
\begin{aligned}
& u_{t}(x, y, z, t)=4 \Delta u(x, y, z, t), \\
& u(x, y, z, 0)=\sin x \sin y \sin z .
\end{aligned}
$$

Solution. We use the formula (3), where $a=2, x=\left(x_{1}, x_{2}, x_{3}\right)=(x, y, z)$ and $t_{0}=0$. Then we have

$$
u(x, y, z, t)=\sum_{n=0}^{\infty} \frac{t^{n}}{n !} \cdot 2^{2 n} \Delta^{n} f(x, y, z) .
$$

Using this expansion we find the exact solution of the problem:

$u(x, y, z, t)=\sum_{n=0}^{\infty} \frac{(4 t)^{n}}{n !} \cdot \Delta^{n}(\sin x \sin y \sin z)=$ $=\sin x \sin y \sin z-\frac{12 t}{1 !} \sin x \sin y \sin z+$

$$
\begin{aligned}
& +\frac{144 t^{2}}{2 !} \sin x \sin y \sin z+\ldots+ \\
& +\frac{(-12 t)^{m}}{m !} \sin x \sin y \sin z+\ldots= \\
& =e^{-12 t} \sin x \sin y \sin z .
\end{aligned}
$$

Example 1.2. Find an solution of the Cauchy problem with an inhomogeneous heat equation:

$$
\begin{gathered}
u_{t}(x, y, z, t)=\Delta u(x, y, z, t)+x y z t, \\
u(x, y, z, 0)=e^{x+y+z} .
\end{gathered}
$$

Solution. We use the replacement

$$
u(x, y, z, t)=v(x, y, z, t)+\frac{x y z t^{2}}{2},
$$

then

$$
\begin{aligned}
v_{t}(x, y, z, t) & =\Delta v(x, y, z, t), \\
v(x, y, z, 0) & =e^{x+y+z} .
\end{aligned}
$$

The solution to this problem will be found using (3), where

$$
a=1, x=\left(x_{1}, x_{2}, x_{3}\right)=(x, y, z) \text { and } t_{0}=0 \text {. }
$$

Then we have the solution of an auxiliary problem of the form

$$
\begin{aligned}
& v(x, y, z, t)=\sum_{n=0}^{\infty} \frac{t^{n}}{n !} \Delta^{n}\left(e^{x+y+z}\right)= \\
& =e^{x+y+z}\left[1+\frac{3 t}{1 !}+\frac{(3 t)^{2}}{2 !}+\ldots+\right]= \\
& =e^{x+y+z+3 t} .
\end{aligned}
$$

Using this solution we find the exact solution of the problem: 


\begin{tabular}{|c|c|c|c|c|c|c|}
\hline \multirow{4}{*}{ Impact Factor: } & ISRA (India) & $=3.117$ & SIS (USA) & $=0.912$ & ICV (Poland) & $=6.630$ \\
\hline & ISI (Dubai, UAE & $=0.829$ & РИНЦ (Russia & $=0.156$ & PIF (India) & $=1.940$ \\
\hline & GIF (Australia) & $=0.564$ & ESJI (KZ) & $=5.015$ & IBI (India) & $=4.260$ \\
\hline & JIF & $=1.500$ & SJIF (Morocco & $=5.667$ & & \\
\hline
\end{tabular}

$$
\begin{aligned}
& u(x, y, z, t)=v(x, y, z, t)+\frac{x y z t^{2}}{2}= \\
& =e^{x+y+z+3 t}+\frac{x y z t^{2}}{2} .
\end{aligned}
$$

$2^{0}$. Setting the second problem. It is required to solve approximately the following Cauchy problem with the Laplace equation in $n$ dimensional space by the Adomian decomposition method and variational iterations method:

$$
\begin{gathered}
\Delta u(x)=0, \quad x \in R^{n}, \\
\left.u\left(x_{1}, x_{2}, \ldots, x_{n}\right)\right|_{x_{n}=x_{0}}=\varphi\left(x_{1}, x_{2}, \ldots, x_{n-1}\right), \\
\left.\frac{\partial u\left(x_{1}, x_{2}, \ldots, x_{n}\right)}{\partial x_{n}}\right|_{x_{n}=x_{0}}=\psi\left(x_{1}, x_{2}, \ldots, x_{n-1}\right)
\end{gathered}
$$

where $x=\left(x_{1}, x_{2}, \ldots, x_{n}\right)$ - is a point in $R^{n}$ space, $\Delta=\frac{\partial^{2}}{\partial x_{1}^{2}}+\frac{\partial^{2}}{\partial x_{2}^{2}}+\ldots+\frac{\partial^{2}}{\partial x_{n}^{2}}$ - Laplace operator, $u(x, t)$ - unknown function (harmonic function), $\varphi$ and $\psi$ - given functions.

Algorithm for solving the second problem. To solve this problem, we will use the Adomian decomposition method and variational iterations method.

2.1. Adomian decomposition method (ADM). By the idea of an ADM, we have:

$$
\begin{aligned}
& \int_{x_{0}}^{x_{n}} d \xi \int_{x_{0}}^{x_{n}} u_{x_{n} x_{n}}(x) d \xi= \\
& =-\int_{x_{0}}^{x_{n}} d \xi \int_{x_{0}}^{x_{n}}\left[u_{x_{1} x_{1}}(x)+u_{x_{2} x_{2}}(x)+\ldots+u_{x_{n-1} x_{n-1}}(x)\right] d \xi \\
& \quad \Rightarrow \\
& u(x)=\varphi(y)+\left(x_{n}-x_{0}\right) \cdot \psi(y)- \\
& -\int_{x_{0}}^{x_{n}} d \xi \int_{x_{0}}^{x_{n}}\left[u_{x_{1} x_{1}}(x)+u_{x_{2} x_{2}}(x)+\ldots+u_{x_{n-1} x_{n-1}}(x)\right] d \xi
\end{aligned}
$$

where $y=\left(x_{1}, x_{2}, \ldots, x_{n-1}\right)-$ is a point in $R^{n}$ space. By the idea of an ADM, we have:

$$
\begin{aligned}
& u(x)=\sum_{n=0}^{\infty} u_{n}(x) \Rightarrow \\
& u_{0}(x)+u_{1}(x)+u_{2}(x)+\ldots= \\
& =\varphi(y)+\left(x_{n}-x_{0}\right) \cdot \psi(y)+ \\
& +\int_{x_{0}}^{x_{n}} d \xi \int_{x_{0}}^{x_{n}}\left\{\left[u_{0}(x)+u_{1}(x)+u_{2}(x)+\ldots\right]_{x_{1} x_{1}}+\right. \\
& \quad+\left[u_{0}(x)+u_{1}(x)+u_{2}(x)+\ldots\right]_{x_{2} x_{2}}+\ldots+ \\
& \left.\quad+\left[u_{0}(x)+u_{1}(x)+u_{2}(x)+\ldots\right]_{x_{n-1} x_{n-1}}\right\} d \xi
\end{aligned}
$$

$$
\begin{aligned}
& u_{0}(x)=\varphi(y)+\left(x_{n}-x_{0}\right) \cdot \psi(y) ; \\
& u_{1}(x)=-\int_{x_{0}} d \xi \int_{x_{0}}^{x_{n}}\left(\left[u_{0}(x)\right]_{x_{1} x_{1}}+\ldots+\left[u_{0}(x)\right]_{x_{n-1} x_{n-1}}\right) d \xi= \\
& =-\frac{\left(x_{n}-x_{0}\right)^{2}}{2 !} \cdot \Delta \varphi(y)-\frac{\left(x_{n}-x_{0}\right)^{3}}{3 !} \cdot \Delta \psi(y) ; \\
& u_{2}(x)=-\int_{x_{0}}^{x_{n}} d \xi \int_{x_{0}}^{x_{n}}\left(\left[u_{1}(x)\right]_{x_{1} x_{1}}+\ldots+\left[u_{1}(x)\right]_{x_{n-1} x_{n-1}}\right) d \xi= \\
& =\frac{\left(x_{n}-x_{0}\right)^{4}}{4 !} \cdot \Delta^{2} \varphi(y)+\frac{\left(x_{n}-x_{0}\right)^{5}}{5 !} \cdot \Delta^{2} \psi(y) ; \ldots ; \\
& u_{k}(x)=-\int_{x_{0}}^{x_{n}} d \xi \int_{x_{0}}^{x_{n}}\left(\left[u_{k-1}(x)\right]_{x_{1} x_{1}}+\ldots+\left[u_{k-1}(x)\right]_{x_{n-1} x_{n-1}}\right) d \xi= \\
& =(-1)^{k} \frac{\left(x_{n}-x_{0}\right)^{2 k}}{(2 k) !} \cdot \Delta^{k} \varphi(y)+ \\
& +(-1)^{k} \frac{\left(x_{n}-x_{0}\right)^{2 k+1}}{(2 k+1) !} \cdot \Delta^{k} \psi(y) \text { and so on. }
\end{aligned}
$$

Finally we find the solution to the problem:

$$
\begin{aligned}
& u(x)=u_{0}(x)+u_{1}(x)+u_{2}(x)+\ldots=\sum_{k=0}^{\infty}(-1)^{k} . \\
& \cdot\left[\frac{\left(x_{n}-x_{0}\right)^{2 k}}{(2 k) !} \cdot \Delta^{k} \varphi(y)+\frac{\left(x_{n}-x_{0}\right)^{2 k+1}}{(2 k+1) !} \cdot \Delta^{k} \psi(y)\right]
\end{aligned}
$$

2.2. Variational iterations method (VIM). To solve the VIM problem, we first use the replacement

$$
u(x)=\int_{x_{0}}^{x_{n}} v(x) d \xi+\varphi(y)
$$

Then equation (9) is reduced to an integrodifferential equation of the form

$$
\begin{aligned}
& v_{x_{n}}(x)+\int_{x_{0}}^{x_{n}}\left[v_{x_{1} x_{1}}(x)+v_{x_{2} x_{2}}(x)+\ldots+v_{x_{n-1} x_{n-1}}(x)\right] d \xi+ \\
& +\Delta \varphi(y)=0,\left.\quad v(x)\right|_{x_{n}=0}=\psi(y)
\end{aligned}
$$

To solve this problem, the formula of VIM is $v_{n+1}(x)=v_{n}(x)+\int_{x_{0}}^{x_{n}} \lambda(\xi)\left[v_{n}(x)\right]_{x_{n}}+$ $+\int_{x_{0}}^{\xi}\left(\left[\tilde{v}_{n}(x)\right]_{x_{1} x_{1}}+\left[\tilde{v}_{n}(x)\right]_{x_{2} x_{2}}+\ldots+\left[\tilde{v}_{n}(x)\right]_{x_{n-1} x_{n-1}}\right) d \eta$ $+\Delta \varphi(y)] d \xi$.

Where $\lambda(\xi)$ - Lagrange multiplier, and for the stationary case $\left.\lambda^{\prime}(\xi)\right|_{\xi=x_{n}}=0,1+\left.\lambda(\xi)\right|_{\xi=x_{n}}=0$ and from here we have $\lambda(\xi)=-1$. Then we have 


\begin{tabular}{|c|c|c|c|c|c|c|}
\hline \multirow{4}{*}{ Impact Factor: } & ISRA (India) & $=3.117$ & SIS (USA) & $=0.912$ & ICV (Poland) & $=6.630$ \\
\hline & ISI (Dubai, UAE & $=0.829$ & РИНЦ (Russia) & $=0.156$ & PIF (India) & $=1.940$ \\
\hline & GIF (Australia) & $=0.564$ & ESJI (KZ) & $=\mathbf{5 . 0 1 5}$ & IBI (India) & $=4.260$ \\
\hline & JIF & $=1.500$ & SJIF (Morocco) & $=5.667$ & & \\
\hline
\end{tabular}

$v_{n+1}(x)=v_{n}(x)-\int_{x_{0}}^{x_{n}}\left[v_{n}(x)\right]_{x_{n}}+$

$+\int_{x_{0}}^{\xi}\left(\left[\tilde{v}_{n}(x)\right]_{x_{1} x_{1}}+\left[\tilde{v}_{n}(x)\right]_{x_{2} x_{2}}+\ldots+\left[\tilde{v}_{n}(x)\right]_{x_{n-1} x_{n-1}}\right) d \eta$

$+\Delta \varphi(y)] d \xi$.

Now applying VIM, we get the following results:

$v_{0}(x)=\psi(y)$;

$v_{1}(x)=\psi(y)-\left(x_{n}-x_{0}\right) \cdot \Delta \varphi(y)-$

$-\frac{\left(x_{n}-x_{0}\right)^{2}}{2 !} \cdot \Delta \psi(y)$;

$v_{2}(x)=\psi(y)-\left(x_{n}-x_{0}\right) \cdot \Delta \varphi(y)-$

$-\frac{\left(x_{n}-x_{0}\right)^{2}}{2 !} \cdot \Delta \psi(y)+\frac{\left(x_{n}-x_{0}\right)^{3}}{3 !} \cdot \Delta \varphi(y)+$

$+\frac{\left(x_{n}-x_{0}\right)^{4}}{4 !} \cdot \Delta \psi(y)$

and so on. Using this expansion we find the formula for solving the problem:

$$
\begin{aligned}
& v(x)=\lim _{k \rightarrow \infty} v_{k}(x)= \\
& =\lim _{k \rightarrow \infty}\left[\psi(y)-\left(x_{n}-x_{0}\right) \cdot \Delta \varphi(y)-\right. \\
& -\frac{\left(x_{n}-x_{0}\right)^{2}}{2 !} \cdot \Delta \psi(y)+\ldots+ \\
& +(-1)^{k} \frac{\left(x_{n}-x_{0}\right)^{2 k-1}}{(2 k-1) !} \cdot \Delta^{k} \varphi(y)+ \\
& \left.+(-1)^{k} \frac{\left(x_{n}-x_{0}\right)^{2 k}}{(2 k) !} \cdot \Delta^{k} \psi(y)\right] .
\end{aligned}
$$

Finally using replacement (12) we find $u(x)=\varphi(y)+\left(x_{n}-x_{0}\right) \cdot \psi(y)+\ldots+$

$+(-1)^{k} \frac{\left(x_{n}-x_{0}\right)^{2 k}}{(2 k) !} \cdot \Delta^{k} \varphi(y)+$

$+(-1)^{k} \frac{\left(x_{n}-x_{0}\right)^{2 k+1}}{(2 k+1) !} \cdot \Delta^{k} \psi(y)+\ldots$

$u(x)=\sum_{k=0}^{\infty}(-1)^{k}\left[\frac{\left(x_{n}-x_{0}\right)^{2 k}}{(2 k) !} \cdot \Delta^{k} \varphi(y)+\right.$

$\left.+\frac{\left(x_{n}-x_{0}\right)^{2 k+1}}{(2 k+1) !} \cdot \Delta^{k} \psi(y)\right]$.

We will check for uniform convergence of a given series with the help of the Weierstrass theorem [4].
If the $\varphi(y)$ and $\psi(y)$ functions is continuous in $y \in R^{n}$ and has continuous derivatives in it, then the following estimate holds for series (11)

$$
\begin{aligned}
& |u(x)|=\mid \sum_{k=0}^{\infty}(-1)^{k}\left[\frac{\left(x_{n}-x_{0}\right)^{2 k}}{(2 k) !} \cdot \Delta^{k} \varphi(y)+\right. \\
& \left.+\frac{\left(x_{n}-x_{0}\right)^{2 k+1}}{(2 k+1) !} \cdot \Delta^{k} \psi(y)\right] \mid \leq \\
& \leq\left|\sum_{k=0}^{\infty}(-1)^{k} \frac{\left(x_{n}-x_{0}\right)^{2 k}}{(2 k) !} \cdot \Delta^{k} \varphi(y)\right|+ \\
& +\left|\sum_{k=0}^{\infty}(-1)^{k} \frac{\left(x_{n}-x_{0}\right)^{2 k+1}}{(2 k+1) !} \cdot \Delta^{k} \psi(y)\right| \leq(14) \\
& \leq \sum_{k=0}^{\infty} \frac{p^{k}}{(2 k) !}+\sum_{k=0}^{\infty} \frac{q^{k}}{(2 k+1) !} \\
& \text { where } p, q=\text { const. }
\end{aligned}
$$

Now we will check for convergence of $\sum_{k=0}^{\infty} \frac{p^{k}}{(2 k) !}$ and $\sum_{k=0}^{\infty} \frac{q^{k}}{(2 k+1) !}$ numerical serieses. On the basis of D'alembert [4] on the convergence of a numerical series with positive coefficients, we have

$$
\begin{aligned}
& \lim _{n \rightarrow \infty} \frac{a_{n+1}}{a_{n}}=\lim _{n \rightarrow \infty} \frac{p^{n+1}}{(2 n+2) !} \cdot \frac{(2 n) !}{p^{n}}= \\
& =\lim _{n \rightarrow \infty} \frac{p}{2 n+2}=0<1 .
\end{aligned}
$$

Then the $\sum_{k=0}^{\infty} \frac{p^{k}}{(2 k) !}$ number series converges. Similarly, it can be shown that the $\sum_{k=0}^{\infty} \frac{q^{k}}{(2 k+1) \text { ! }}$ number series also converges. From the validity of the estimate (14) and on the basis of the Weierstrass theorem, series (11) uniformly converges. Then, the function $u(x)$ is a solution to problem (9)-(10).

Note: If one $q(x)$ particular solution of the Poisson equation is known

$$
\Delta u(x)=f(x),
$$

where $f(x)$ - known function, then replacing $v(x)=u(x)+q(x)$ equation (15) can be reduced to the form $\Delta v(x)=0 \quad$ (16), and the solution (16) can be found using (11).

Below are the possibilities of applying formulas (11) or $\left(11^{*}\right)$ in some examples.

Example 2.1. Find an solution of the Cauchy problem with the three-dimensional Laplace equation:

$$
\Delta u(x, y, z)=0,
$$

$$
u(x, y, 0)=x \sin y, \quad u_{z}(x, y, 0)=\cos y \text {. }
$$




\begin{tabular}{|c|c|c|c|c|c|c|}
\hline \multirow{4}{*}{ Impact Factor: } & ISRA (India) & $=3.117$ & SIS (USA) & $=0.912$ & ICV (Poland) & $=6.630$ \\
\hline & ISI (Dubai, UAE & $=0.829$ & РИНЦ (Russia) & $=0.156$ & PIF (India) & $=1.940$ \\
\hline & GIF (Australia) & $=0.564$ & ESJI (KZ) & $=\mathbf{5 . 0 1 5}$ & IBI (India) & $=4.260$ \\
\hline & JIF & $=1.500$ & SJIF (Morocco) & $=5.667$ & & \\
\hline
\end{tabular}

Solution. We use the formula (11), where $x_{n}=z, x_{0}=0$, $\varphi(y)=x \sin y, \psi(y)=\cos y$. Then we have $u(x, y, z)=\sum_{k=0}^{\infty}(-1)^{k}\left[\frac{z^{2 k}}{(2 k) !} \cdot \Delta^{k}(x \sin y)+\right.$ $\left.+\frac{z^{2 k+1}}{(2 k+1) !} \cdot \Delta^{k}(\cos y)\right]$.

Then we find the exact solution of the problem: $u(x, y, z)=x \sin y\left(1+\frac{z^{2}}{2 !}+\frac{z^{4}}{4 !}+\ldots\right)+$ $+\cos y\left(z+\frac{z^{3}}{3 !}+\frac{z^{5}}{5 !} \ldots\right)=$ $=x \sin y \operatorname{ch} z+\cos y \operatorname{sh} z$.

Example 2.2. Find an solution of the Cauchy problem with the three-dimensional Poisson equation.

$$
\begin{gathered}
\Delta u(x, y, z)=1, \quad u(x, y, 0)=\frac{x^{2}}{2}, \\
u_{z}(x, y, 0)=e^{2 x} \sin y .
\end{gathered}
$$

We first introduce the notation of the from: $u(x, y, z)=v(x, y, z)+\frac{x^{2}}{2}$, then we have the problem

$$
\begin{gathered}
\Delta v(x, y, z)=0, \quad v(x, y, 0)=0, \\
v_{z}(x, y, 0)=e^{2 x} \sin y .
\end{gathered}
$$

To find the function $v(x, y, z)$ we use formula (11), where $\quad x_{n}=z, \quad x_{0}=0$, $\varphi(y)=0, \psi(y)=e^{2 x} \sin y$. Then we have the solution of an auxiliary problem of the form

$$
\begin{aligned}
& v(x, y, z)=\sum_{k=0}^{\infty}(-1)^{k} \frac{z^{2 k+1}}{(2 k+1) !} \cdot \Delta^{k}\left(e^{2 x} \sin y\right)= \\
& =e^{2 x} \sin y\left(z-\frac{z^{3}}{3 !}+\frac{z^{5}}{5 !}+\ldots\right)=e^{2 x} \sin y \sin z .
\end{aligned}
$$

Then we find the exact solution of the problem:

$$
\begin{aligned}
& u(x, y, z)=v(x, y, z)+\frac{x^{2}}{2}= \\
& =e^{2 x} \sin y \sin z+\frac{x^{2}}{2} .
\end{aligned}
$$

\section{Conclusions.}

In this work, VIM and ADM were successfully applied to solve the Cauchy problem with the heat dissipation and Laplace equations. It is obvious that VIM an ADM are very powerful and effective methods for finding analytical solutions for wide classes of nonlinear problems. It is worth noting that these two methods are a quick convergence of solutions. Both methods are convenient and effective for solving such problems, and they also do not require large computer memory and discrimination of the variables $t$ and $x$, and the application of ADM to the problems discussed has more advantages than VIM and most other methods; it overcomes the difficulties in calculating other methods and auxiliary parameters; it helps us to obtain a solution for smaller approximations. Also, the ADM does not require changing some parameters in the equation, therefore, the calculations are simple and straightforward.

\section{References:}

1. Abdirashidov, A., Kadirov, N. X., Ortikov, B. B., \& Abdurashidov, A. A. (2018). Solution of fractional telegraph and diffusion equations using the approximation methods. International Scientific Journal «Theoretical \& Applied Science», №10, 101-107.

2. Abdirashidov, A., Ortiqov, B. B., Qadirov, N. X., \& Abdurashidov, A. A. (2018). Exact solution of fractional diffusion equations using the variational iteration method and Adomian decomposition method. International Scientific Journal «Theoretical \& Applied Science», №5, 101-107.
3. Abdurashidov, A. A., Ortiqov, B. B., Qadirov, N. X., \& Abdirashidov, A. (2018). Exact solution of nonlinear equations BurgersHuxley, Korteweg-de Vries-Burgers and Klein-Gordon using the modified simple equation method. International Scientific Journal «Theoretical \& Applied Science», №3, 101-107.

4. Azlarov, T. A., \& Mansurov, X. (1989). Matematicheskiy analiz II chast. (p.424). Tashkent: O'qituvchi.

5. Bisadze, A. V., \& Kalinichenko, D. F. (1985). Sbornik zadach po uravneniyam 


\begin{tabular}{|c|c|c|c|c|c|c|}
\hline \multirow{4}{*}{ Impact Factor: } & ISRA (India) & $=3.117$ & SIS (USA) & $=0.912$ & ICV (Poland) & $=6.630$ \\
\hline & ISI (Dubai, UAE & $=0.829$ & РИНЦ (Russia) & $=0.156$ & PIF (India) & $=1.940$ \\
\hline & GIF (Australia) & $=0.564$ & ESJI (KZ) & $=\mathbf{5 . 0 1 5}$ & IBI (India) & $=4.260$ \\
\hline & JIF & $=1.500$ & SJIF (Morocco) & $=5.667$ & & \\
\hline
\end{tabular}

matematicheskoy fiziki. Ucheb. posobiye dlya mexaniko-matemat. i fiz. spes. vuzov. - 2-ye izd., dop. (p.310). M.: Nauka.

6. Ibragimov, N. X. (2007). Prakticheskiy kurs differensialnbix uravneniy $i$ matematicheskogo modelirovaniya. (p.421). Nijniy Novgorod, Nijegorodskogo gosuniversiteta.

7. Kudryashov, N. A. (2010). Metodi nelineynoy matematicheskoy fiziki. Uchebnoye posobiye. 2-ye izd. (p.368). M.: Dolgoprudniy: Intellekt.

8. He, J. H. (2007). Variational iteration method - some recent results and new interpretations,
Journal of Computational and Applied Mathematics, 207(1), 3-17.

9. He, J. H., \& Wu, X. H. (2007). Variational iteration method. New development and applications, Computers and Mathematics with Applications, 54 (7-8), 881-894.

10. Wazwaz, A. M. (2011). Linear and Nonlinear Integral Equations. (p.658). Higher Education Press, Berlin Heidelberg.

11. Wazwaz, A. M. (2009). Partial Differential Equations and Solitary Waves Theory. (p.761). Higher Education Press, Berlin Heidelberg. 